\title{
SEJARAH PERKEMBANGAN TEATER MAKYONG DI PULAU PANJANG TAHUN 1970-2016
}

\section{HISTORY OF THE DEVELOPMENT OF THE MAKYONG THEATER IN PULAU PANJANG ISLAND OF 1970-2016}

\author{
Dimasari $^{1}$, Arnesih $^{2}$ \\ ${ }^{1}$ (ProdiPendidikan Sejarah, Fakultas Fkip, Universitas Riau Kepulauan, Indonesia) \\ ${ }^{2}$ (Prodi Pendidkan Sejarah, Fakultas Fkip Universitas Riau Kepulauan, Indonesia) \\ IDimasari@gamil.com, ${ }^{2}$ arnesih@fkip.unrika.ac.id
}

\begin{abstract}
ABSTRAK
Penelitian ini bertujuan untuk mengetahui sejarah perkembangan teater Makyong di Pulau Panjang tahun 1970-2016. Teknik pengumpulan data dalam penelitian ini adalah teknik Wawancara, teknik Observasi, dan teknik Dokumentasi. Setelah sumber-sumber dikumpulkan kegiatan penelitian berikutnya yaitu melakukan teknik analisis data yaitu mengumpulkan sumber-sumber sebagai data (Heuristik), melakukan kritik sumber (Verifikasi), kemudian melakukan penafsiran (Interpretasi) dan yang terakhir dilakukan peneliti yaitu kegiatan historiografi yakni menulis dalam bentuk karya ilmiah. Berdasarkan penelitian ini menunjukkan bahwa masih ada masyarakat yang masih mengembangkan kesenian tradisional Melayu yang bersifat turun-temurun dari zaman dahulu yang diwariskan secara lisan yang terletak di Pulau Panjang, Kelurahan Setoko, dan Kecaman Bulang. Dari penelitian Teater Makyong ini dikatakan bahwa cerita-cerita yang dipentaskan merupakan cerita rakyat dari istana zaman dahulu. Perkembangan Makyong ini juga terlihat dari zaman dahulu hingga sekarang. Zaman dahulu pertunjukan Makyong digunakan untuk beberapa acara atau hal seperti hiburan di istana kerajaan, obat untuk orang sakit dan mata pencaharian. Namun seiring peerkembangan zaman keberadaan Makyong mulai melemah dan bisa dikatakan sebagai slogan budaya Melayu saja, akan tetapi Makyong ini juga tidak lepas dari mata pencaharian bagi pelakonnya dan hiburan di masyarakat khususnya masyarakat Melayu hingga saaat ini.
\end{abstract}

Kata kunci: Kebudayaan Melayu, Teater Makyong Pulau Panjang

\begin{abstract}
ABSTRACK
Makyong Theater is one of the traditional Malay art that developed in Pulau Panjang,. This study aims to determine the history of Makyong theater development in Pulau Panjang year 1970-2016. Data collection techniques in this study are Interview techniques, Observation techniques, and Documentation techniques. After the sources are collected the next research activity is doing data analysis technique that is collecting the sources as data (Heuristic), doing source criticism (Verification), then doing interpretation (Interpretation) and the last done by the researcher is historiografi activity ie writing in the form of work scientific. Based on this research indicates that there are still people who still develop traditional Malay art that is hereditary from ancient times passed on orally located in Pulau Panjang, Setoko Subdistrict, and Bulaman Calamity. From Makyong Theater research it is said that the stories that are staged are the folklore of the ancient palace. The development of Makyong is also seen from ancient times until now. Ancient Makyong performances were used for some events or things like entertainment in the royal palace, medicine for the sick and livelihood. However, as the peerkembangan of Makyong's existence began to weaken and can be regarded as the only Malay cultural slogan, but this Makyong also can not be separated from the livelihood for pelakonnya and entertainment in the community, especially the people of Malay until this saat.
\end{abstract}


Keywords: Malay culture, Makyong Pulau Panjang Theater

\section{PENDAHULUAN}

Kepulauan Riau merupakan tanah melayu yang banyak memiliki warisanwarisan budaya, salah satunya Kota Batam. Batam merupakan salah satu kota yang kaya akan kebudayaan melayu, seperti adat istiadat, tari tradisional, alat musik tradisional, permainan tradisional, pentas seni tradisional yang telah memperkaya keanekaragaman budaya. Dari kebudayaan itu masyarakatlah yang menciptakaannya.

Penduduk asli di Batam orang Melayu, oleh karena itu pada dasarnya kebudayaan Kota Batam yang dominan di dalamnya adalah kebudayaan Melayu. Salah satu wujud kebudayaan Melayu yang dimiliki Provinsi Kepulauan Riau (KEPRI) khususnya di Batam yaitu seni pertunjukan Makyong (Teater Makyong).

Dalam upaya pengembangan ini kita banyak mengalami masalah di karenakan banyaknya kebudayaan luar yang masuk. Meski upaya pelestarian merupakan pekerjaan yang berat, namun ada beberapa masyarakat yang menyadari akan pentingnya mengembangkan kebudayaan tersebut, sehingga walaupun kebudayaan itu hampir tersingkirkan masih ada yang melestarikannya. Di Provinsi Kepulauan Riau, khususnya Kota Batam tepatnya berada di Pulau Panjang yang masih mengembangkan tradisi kebudayaan melayu tersebut yaitu Makyong.

\section{METODOLOGI}

Jenis penelitian ini adalah penelitan kualitatif dengan metode Historis. Penelitian kualitatif sebagai model yang dikembangkan oleh Mazhab Baden yang besinergi dengan aliran filsafat fenomenologi menghendaki pelaksanaan penelitian menghendaki penelitian berdasarkan pada situasi wajar (natural setting) sehingga kerap orang juga menyebutnya sebagai metode naturalistik. (Idrus, 2009:23).

Penelitian historis adalah usaha untuk menetapkan fakta dan mencapai kesimpulan mengenai hal-hal yang telah lalu. Secara sistematis dan obyektif, ahli sejarah mencari, mengavaluasi dan menafsirkan bukti-bukti yang dapat dipakai utnk mempelajari masa lalu. Berdasarkan bukti yang dikumpulakan, ahli sejarah menarik kesimpulan mengenai masa lalu guna memperkaya pengetahuan kita tentang bagaimana 
dan mengepa sesuatu kejadian di masa lalu terjadi serta proses bagaimana masa lalu itu menjadi masa kini. Hasil yang diharap adalah meningkatnya pemahaman tentang kejadian masa kini serta diperolehnya dasar yang lebih rasional utnuk melakukan pilihan-pilihan di masa kini. (Furchan, 2004:473)

\section{PEMBAHASAN}

\section{Sejarah Awal Masuknya Teater Makyong di Pulau Panjang}

Makyong diasaskan di Kerajaan Pattani yang kini merupakan sebahagian dari Thailand. Menurut Hikayat Patani Mak Yong di bawa ke Kelantan lebih dari 200 tahun dahulu. Dari situ ia berkembang ke Kedah dan negeri-negeri lain. Semasa di Patani, Makyong biasanya dipersembahkan di istana sehingga 1920 di mana ia sering dipertontonkan di kalangan orang biasa.

Adapun menurut Pak Man (Abdul Rahman di Mantang Arang, Kabupaten Kepulauan Riau pada 1972 ), dalam (Zam, 2004:512) seni pertunjukan Makyong berasal dari tiruan permainan yang dilakonkan oleh harimau jadi-jadian, " suatu hari ada seorang lelaki yang pergi masuk hutan dan tersesat. Untunglah ia berjumpa sebuah kampung dan orang yang tinggal di ujung kampung itu, berbaik hati mengajaknya bermalaman di pondoknya. Setelah selesai makan, tuan rumah berpesan, "jangan kemana-mana, jangan pergi ke luar rumah. Tutup pintu tingkap dan tidurlah, saya ada kerja sedikit". Hari pun malam. Begitu hari malam, orang kampung itu berubah menjadi harimau semuanya. Lalu terdengar bunyi gong dan tambur, amatlah bagus bunyinya. Orang yang sesat tadi mengintip dari celah-celah dinding. Rupanya harimau jadi-jadian itu sedang bersenang-senang dengan suatu permainan penghibur hati, pengobat penat di siang hari. Begitu permainan selesai, mereka pun letih dan terkapar tidur dan tak sempat mencium bau manusia. Besoknya orang yang sesat tadipun balik ke kampungnya. Permainan harimau jadi-jadian itu ditirunya dan dimainkannya di kampungnya. Konon, itulah asal mulanya Makyong.

Para peneliti, atau pengkaji seni pertunjukan Makyong seperti Walter Skeat (1976) berusaha mencari di mana tempat asal dan bagaimana terjadinya sampai ketempat yang mengembangkan budaya Makyong. Dilihat dari beberapa macam ritual yang di lakukan dalam pertunjukan Makyong ada peneliti yang memperkirakan 
Makyong berasal dari kepercayaan animisme dan terpakai dalam pengobatan tradisional. ( zam, 2004:513).

Di tahun 1970-an pementasan Makyong dipentaskan di tengah-tengah halaman kampung atau lapangan, seperti Makyong yang pernah ditampilkan di Setokok. Untuk tempat bermain Makyong dibuat tempat khusus yang disebut bangsal. Pertunjukan Makyong dilakukan sederhana. Adapun persiapannya seperti menyediakan alat-alat musik, panggung, pengaturan panggung, dan latihan sebelum tampil. Persembahan Makyong di Pulau Panjang masih mementaskan persembahan makyong dengan ciri-ciri tradisional.

Pementasan Makyong tidak menuntut set properti, dekorasi, atau layar untuk pergantian babak. Apabila Makyong dipentaskan di lapangan terbuka, tempat pentas harus di beri atap yang menggunakan bubungan dengan enam buah tiang penyangga. Pada kayu yangt melintang yang dihiasi daun kelapa muda. Jika dimainkan di istana maka makyong dimainkan di atas panggung.

Pertunjukan Makyong dilakukan ketika ada undangan dari luar untuk tampil seperti acara pernikahan. Mereka tampil dari satu pulau ke pulau yang lain. Beberapa tahun yang lalu untuk menyeberang ke pulau mereka menggunakan perahu layar sebagai alat transportasi. Dua minggu sebelum pementasan, para seniman Makyong engumpulkan orang (para pemain) musik seperti dari Bintan, Batam, dan pulau sekitarnya.

Di tahun 1980-an seniman Makyong Pulau Panjang sering mewakili Batam tampil di acara-acara seni dan festival. Mereka tampil di Pekanbaru, Jakarta, Yogyakarta, Bandung, dan kota lain. Sesekali mereka diundang ke Melaka, Malaysia. Dalam pementasan Makyong masih dikaitkan dengan unsur-unsur yang bermakna spiritual seperti memeohon selamat, mengucapkan terima kasih agar selamat keluar dari malapetaka atau mendapat rahmat tertentu dari maha kuasa, sudah tentu dalam khas kebudayaan melayu hal tersebut masih ada. Teater Makyong ditempat asalnya masih di laksanakan dalam kepentingan yang demikian dan didahului dengan "Buka Tanah (Pembuka Pertama)" yang berhubungan dengan doa restu untuk mendapatkan keselamatan pemain dan penontonnya. Tapi sekarang tidak ada upacara spiritual yang di 
pentaskan pada zaman-zaman dahulu, hanya saja memohon keselamatan agar tidak diganggu oleh para makhluk-makhluk gaib (halus) yang telah mendahului kita.

\section{Sejarah Perkembangan Teater Makyong di Pulau Panjang}

Perkembangan kebudayaan Melayu di kota Batam berawal dari Walikota Madya Batam yang pertama tahun 1983 yang bernama bapak Usman Draman dan pada masa itu Batam masih kota Madya. Masa kegemilangan budaya melayu dibatam saat itu sangat luar biasa. Pulau Panjang juga merupakan daerah wisata diwilayah kota Batam berdasarkan penyuluhan wisata (2010) dari dinas pariwisata dan kebudayaan kota Batam tentang pengurusan Dewan Kesenian kota Batam.

Perkembangan Makyong di Pulau Panjang tahun 1970 sangat pesat. Seniman Makyong di Pulau Panjang melakukan pertunjukan Makyong ke pulau-pulau menggunakan perahu layar. Selain sebagai kesenian budaya Melayu Makyong di jadikan sebagai mata pencaharian mereka. Tahun 1995, merupakan puncak keberhasilan dan berkembangnya Makyong sampai seniman Pulau Panjang yang telah mengharumkan nama Batam sebagai seniman Melayu yaitu bapak Basri yang meninggal dunia sejak tahun 2000, seolah-olah sudah tidak ada Makyong lagi, karena pemeran-pemeran Makyong sudah banyak meninggal. Pada tahun 2006 Makyong di Pulau Panjang sudah mulai menurun.

Dalam perkembangan Makyong di tahun yang lalu pada malam harinya seniman menyediakan tiket masuk untuk menyaksikan pentas drama rakyat Makyong dengan menggunakan tiket. Tiket tersebut tidak hanya digunakan untuk menonton Makyong saja melainkan untuk menyaksikan hiburan-hiburan tradisional melayu lainnya. Para seniman berkeliling dari satu pulau ke pulau lainnya, terkadang diundang diacara perkawinan maupun acara-acara resmi lainanya, untuk menampilkan seni drama rakyat Makyong sebagai hiburan masyarakat pada zaman.

Seni pentas drama rakyat Makyong yang dikenal di Provinsi Kepri tepatnya di Kota Batam, merupakan akar budaya Melayu yang ada di Batam yaitu di Pulau Panjang. Tahun 2000 seni drama Makyong masih diminati oleh masyarakat. Namun sejak tahun 2006, eksistensi seni drama Makyong mulai menurun, dalam arti jarang ada undangan 
dan permintaan dari masyarakat. Ketika perayaan besar saja Makyong ditampilkan seperti acara kenduri seni Melayu salah satunya, sampai di tahun 2013 masih menurun tidak ada perkembangan. Sangat jauh dari tahun-tahun sebelumnya Makyong sering ditampilkan baik diluar kota maupun di pulau-pulau lainnya, di luar negeri, acara pernikahan, acara kecamatan maupun kelurahan.

Hal ini dikarenakan adanya pengaruh budaya-budaya lain yang sudah berkembang baik dalam maupun luar negeri. Disamping itu seni drama Makyong di pulau Panjang juga mempunyai kelemahan, diantaranya kurangnya daya jual atau promosi akibat kurangnya perhatian oleh pemerintah.

\section{a. Struktur Seni Pertunjukan Makyong}

Dalam pertunjukan Makyong banyak terdiri dari berbagai struktur untuk pementasannya, sehingga dalam pertunjukan Makyong dapat berjalan dengan lancar. Makyong merupakan sejenis tarian Melayu tradisional. Drama tari Makyong ini merupakan sebagai suatu bentuk drama-tari Melayu yang menggabungkan unsur-unsur ritual, lakonan dan tarian yang digayakan, musik vokal dan instrumental, lagu, cerita dan teks percakapan yang formal dan bersahaja. Seni pertunjukan Makyong juga termasuk seni pertunjukan tarian rakyat yang lebih mengungkapkan kehidupan rakyat pada umumnya yang berbentuk tarian gembira atau tarian pergaulan seperti Mendu dan Bangsawan.

Adapun tarian rakyat adalah tarian yang tumbuh dan berkembang di dalam masyarakat, yang kemudian diperbuat pula secara turun-temurun dan kemudian menjadi milik bersama. Tari rakyat lahir begitu adanya, tanpa campur tangan dari hasil pikiran dari para intelektual, melainkan lebih merupakan pencerminan pengalaman-pengalaman bersama dari suatu masyarakat (Zam, 2004:600).

a. Tuan Putri

Tuan putri berperan sebagai istri dari raja atau pak Yong dalam sebuah pemerintahan dalam kerajaan.

b. Awang pengasuh

Awang pengasuh berperan sebagai orang kepercayaan raja atau orang terdekat yang selalu di perintahkan oleh raja. 
c. Inang pengasuh

Inang pengasuh berperan sebagaimana awang, inang juga merupakan orang kepercayaan dan pesuruh dari tuan puteri (istri raja) dalam kegiatan istana.

d. Wak-wak

Wak-wak merupakan pengikut atau kepercayaan dari raja (awang), ketika awang mendapat perintah dari raja (pak Yong), para wak-wak ikut serta membantu awang dalam melaksanakan tugas yang diperintahkan oleh raja. wak-wak terbagi atas Wak Prambon, Wak Pranpaye, Wak Pramkunyit, Wak Pramutan, Wak Prananggo, dan banyak lagi nama wak-wak yang lainnya sesuai dengan profesi masing-masing.

e. Dayang-dayang

Dayang-dayang merupakan gadis-gadis muda yang berperan sebagai penari atau pendamping tuan puteri dan merupakan orang pembantu inang dalam melaksanakan tugas istana, nama-nama dayang juga diambil dari berbagai nama

\section{b. Cerita}

Orang melayu yang sebagian besar bermukim di daerah pesisir memiliki ragam kesenian yang sedemikian banyaknya di antaranya adalah seni tari, seni pertunjukan seperti Makyong (dalam lingkup teater ), boria, Wayang Cecak, berzanji, Mendu dan bangsawan (Zam, 2004:596).

Cerita yang disajikan dalam pementasan Makyong sebagian besar sudah dikenal secara luas, karena cerita Makyong berasal dari cerita rakyat atau warisan dari tukang cerita istana. Tidak ada peninggalan tertulis tentang cerita Makyong. Semua lakon tertular dari tradisi lisan. Cerita-cerita dalam Makyong menjalani beberapa tahap perkembangan. Bermula dengan cerita dalam kerajaan maupun di luar kerajaan, cukup banyak catatan tentang Makyong dibuat oleh seniman Makyong di pulau Panjang.

Cerita yang diangkat berbeda-beda sesuai dengan topik dan judul cerita. Cerita dalam pementasan Makyong berasal dari cerita rakyat atau warisan dari istana. Menurut hasil wawancara Cerita yang selalu di pentaskan oleh seniman Makyong pulau Panjang adalah :

a. Putri Siput Gondang 
Dalam cerita Putri Siput Gondang seorang raja memerintahkan awang pengasuh beserta wak-wak untuk menjemput mak bedan dikarenakan permaisuri raja ingin melahirkan. Perjalanan Awang dan Wak-wak cukup jauh karena rumah mak bedan terletak di ujung suatu negeri dan harus beristirahat sejenak di hutan, kemudian Awang dan wak-wak bergegas untuk melanjutkan perjalanan. Di tengah perjalanan Awang dan para wak-waknya bertemu harimau dan di serang oleh harimau itu yang menyebabkan beberapa wak-wak ada yang cidera. Karena Awang memiliki keahlian dan kemahiran maka wak-wak bisa diselamatkan. Setelah sampai ke rumah mak bedan, mak bedan pun dibawa ke istana. Selang beberapa waktu lahirlah anak raja, setelah permaisuri melahirkan mak bedan memanggil Awang dan berkata agar peristiwa ini dirahasiakan "biarlah pecah di perut asalkan jangan pecah di mulut". Kemudian mak bedan memberi tahu kepada Awang bahwasannya tuan putri melahirkan seekor siput. Awang sangat kaget mendengar kabar tersebut. Kemudian awang memberi tahu kepada raja, awang tidak sanggup untuk mengatakannya, setelah raja mengetahui kabar tuan putri melahirkan seorang siput, raja sangat murka sehingga raja langsung memerintahkan awang untuk membuang siput ke negeri lain yaitu ke Pantai Teluk Sembilan.

Awang dan para wak-wak membawa siput itu dengan bersedih hati ke Pantai Teluk Sembilan, kemudian kembali ke sitana. Keesokan harinya raja melihat permaisuri sedang bersedih hati, kemudian raja memerintahkan awang untuk memanggil mak inang untuk menghibur permaisurinya. Inang pun bergegas memanggil dayang-dayang untuk membawa tuan putri ke taman bunga untuk menghibur tuan putri, dan akhirnya tuan putri pun terhibur. Beberapa bulan waktu berselang tuan putri sangat menginginkan makanan laut (siput). Raja pun langsung memerintahkan awang untuk pergi mencari siput yang banyak terdapat di pantai Teluk Sembilan. Pada saat mencari siput, awang dan para wak-wak mendengar suara bunyi-bunyian. Mendengar hal itu awang dan para wak-wak menghadap raja dan melaporkan kejadian tersebut. Raja kemudian memerintahkan awang dan wak-wak untuk kembali ke tempat kejadian itu untuk menyelidiki peristiwa itu. Akhirnya mereka menjumpai benda yang besar (siput) dan langsung di bawa ke istana dengan cara bergotong royong. 


\section{b. Kijang Emas Tandok Lencane}

Kijang Emas Tandok Lencane mengisahkan seorang dewa. Kijang Emas ini merupakan simbol dalam suatu pemerintahan, sebuah cerita bagaimana sebuah negeri mendapatkan kijang emas, karna kijang emas ini sangat berharga. Sehingga kijang emas ini melambangkan negeri yang makmur bagi rakyatnya. Cerita ini menarik sekali karena kijang emas di dapat dari orang yang berhubungan dengan orang kayangan.

c. Raja Sang Nyanye

Pada cerita ini raja Syahnaya menginginkan rakyatnya untuk tidak bertengkar dan saling mengadu kepadanya segala permasalahan dan saling mengeluh. Raja Syahnaya menginginkan rakyatnya makmur dan tentram. Adanya permasalahan tersebut raja membuat suatu keputusan siapa saja yang berbuat salah dan memulai perkelahian akan di hukum. Raja Syahnaya selalu memberikan hukuman sesuai dengan kecil dan besarnya permasalah yang di lakukan.

\section{d. Raja Bongsu}

Raja Bongsu menceritakan tentang sumpahan dimana dua orang kakak beradik yang disumpah oleh ibunda di kayangan. Penyebabnya karena keduanya sling tidak sepaham. Kakaknya disumpah menjadi harimau dan adiknya disumpah menjadi seekor katak. Pak katak dalam peran itu seperti orang yang bodoh, namun sebenarnya hebat. Pada suatu hari selendanh tuan putri dicuri olah pak katak. Kahirnya tuan putri, awang dan wak-wak membuat suatu tipu muslihat, dengan tipu muslihat itu pak katak kalah di pasung, di arak keliling kampung. Namun pak katak memiliki kesaktian dapat menyembuhkan penyakit. Setelah memenuhi syarat-syarat sebagai akibat perlakuannya, maka dia berubah menjadi seorang pemuda tampan dan nikah bersama seorang putri.

\section{e. Sang Kiwi}

Dalam cerita Sang Kiwi raja memiliki istri dua. Salah satunya sang Kiwi yang berwatak kejam, jahat dan berambisi mengangkat putranya menjadi raja. Namun salah satu istri raja berwatak baik. Salah satu anak sang Kiwi meninggal. Sebagai balas dendam karena selama hidupnya berwatak kejam dan jahat akhirnya para awang dan wak-wak membalasnya sampai akhirnya sang Kiwi meninggal. 


\section{KESIMPULAN DAN SARAN}

Ada beberapa faktor yang menyebabkan seni pertunjukan tradisional Makyong pada zaman dahulu sangat banyak diminati oleh masyarakat, dikarenakan dahulunya tidak ada hiburan selain pertunjukan dan pementasan seni kebudayaan Melayu seperti joget Dangkong lebih terkhusus pementasan Makyong. Pementasan Makyong ini pula selain sebagai kesenian tradisional Melayu, dia juga sebagai mata pencaharian bagi pemeran-pemerannya dan pada saat itu pula tidak ada kabudayaan lain yang masuk sehingga banyak masyarakat yang sangat antusias dalam pertunjukan Makyong ini. Namun seiring perkembangan zaman pementasan Makyong ini mulai menurun dikarenakan banyak seniman-seniman dalam pementasan Makyong ini sudah tidak ada atau meninggal dunia dan kurangnya dukungan atau sponsor dari masyarakat dan pemerintah dalam mengembangkan kebudayaan Makyong ini sehingga generasi muda kurang dalam keinginan untuk berkecimpung dalam seni pentas tradisional Melayu terutama Makyong. Seiring perkembangan zaman itu pula banyak budaya-budaya lain selain Melayu yang sudah masuk ke Batam.

Adapun saran bagi pemerintah daerah agar tetap melestarikan dan mengembangkan seni kebudayaan Melayu khususnya seni pementasan tradisional Makyong dan memberi dukungan kepada seniman-seniman Melayu yang telah mengharumkan nama daerah atau kota, sehingga kesenian Melayu tersebut tidak akan memudar ditelan zaman dan bisa menjadi kebanggaan baik bagi masyarakat setempat maupun warga kota Batam dan bagi para pencinta kesenian Melayu di luar kota Batam.

\section{DAFTAR PUSTAKA}

Desfaliana.(2016). Analisis Nilai-nilai Budaya Melayu Dalam Teater Makyong.Artikel E-Journal. Universitas Maritim Raja Ali Haji Tanjung Pinang. Skripsi. Tidak diterbitkan, diunduh pada tanggal 23 April 2017.

Furchan, H.A. (2004). Pengantar Penelitian Dalam Pendidikan. Yogyakarta: Pustaka Pelajar.

Hadriyanti, Elfia. (2010). Eksistensi tari Tradisi Gelombang pada Upacara Adat Batagak Penghulu di Nagari Padang Laweh Kecamatan Banuhampu Sungai Puar Kabupaten Agam Sumatera Barat. Skripsi. Tidak diterbitkan. 
Historia: Jurnal Program Studi Pendidikan Sejarah

Vol. 2 No. 2 (2017):41-51

P-ISSN 2301-8305

E- ISSN 2599-0063

Hidayat, Budi. (2014). Kesenian Tradisional Joget Dangkong di Pulau Panjang Tahun 1980-2010. Skripsi.Tidak diterbitkan.

Ibrahim, Dr. (2015). Metodologi Penelitian Kualitatif. Bandung: Alfabeta cv.

Idrus, Muhammad. (2009). Metode Penelitian Ilmu Sosial. Yogyakarta: Penerbit erlangga.

Kuntowijoyo.(1995). Pengantar Ilmu Sejarah. Yogyakarta: Yayasan Bentang Budaya.

Maleong, Lexy. J.(2013). Metodologi Penelitian Kualitatif. Bandung: PT Remaja Rosdakarya.

Prasetya, J.T, dkk. (2011). Ilmu Budaya Dasar. Jakarta: Renika cipta.

Setiadi, E.M. (2011). Ilmu Sosial Budaya Dasar. Jakarta: Predana Media Group.

Sjamsuddin, Helius. (2012). Metodologi Sejarah. Yogyakarta: Penerbit Ombak.

Susanti, Evi. (2013). Eksistensi Drama Rakyat Makyong di Pulau Panjang Tahun 19992012. Skripsi, tidak diterbitkan.Universitas Riau Kepulauan Batam.

Sutrisno, Edy, dkk. (2007). Becermin sejarah Menyongsong Batam Masa Depan. Batam: PT Batam link Publisher.

Yusep.(2014). Pelestarian Tradisi Jampe Pada Masyarakat Kampung Naga Tasikmalaya. Skripsi, tidak diterbitkan.Universitas Islam Negeri Sunan Kalijaga.

Zam, Mochtar. (2004). Butang Emas. CV. Data Makmur Setia Jakarta. Yayasan Pustaka Bunda. 